\title{
Case Series: Is Minimal Coronary Artery Disease a Prognostic Indicator in Dilated Cardiomyopathy?
}

\author{
Shahood Ajaz Kakroo ${ }^{1} \quad$ Yalampati Rama Kishore $^{1}$ \\ ${ }^{1}$ Department of Cardiology, Nizam's Institute of Medical Sciences, \\ Punjagutta, Hyderabad, Telangana, India \\ Ind J Car Dis Wom 2021;6:221-227.
}

\begin{abstract}
Address for correspondence Shahood Ajaz Kakroo, Department of Cardiology, Nizam's Institute of Medical Sciences, Punjagutta, Hyderabad 500082, Telangana, India (e-mail: shahood.cardio@gmail.com).
\end{abstract}

\begin{abstract}
Keywords

- dilated cardiomyopathy

- coronary artery disease

- heart failure

- mortality

Background The aim of this study was to study the prognostic implications of minimal coronary artery disease (CAD) in patients with dilated cardiomyopathy (DCMP) in terms of mortality and hospitalization due to heart failure.

Methods One-hundred sixty-three patients with DCMP were recruited for this study. Out of these, $61.9 \%(n=101 ; 62.4 \%$ men) patients were without associated minimal CAD and 38\% ( $n=62 ; 66.1 \%$ men) with associated minimal CAD (stenosis $<50 \%$ ), and their risk factor profile was noted. These patients were followed for 30 months, with mortality being the primary endpoint, and hospitalization secondary to cardiac decompensation in the form of heart failure was denoted as the secondary endpoint. Results In our study, independent significant predictors of CAD were age $(p=0.002)$, hypertension ( $p=0.001)$, diabetes $(p<0.001)$, and smoking $(p=0.023)$. The presence of minimal CAD in DCMP patients as a predictor of mortality was not significant (odds ratio [OR]: $1.69,95 \%$ confidence interval $[\mathrm{Cl}]: 0.62-4.62, p=0.303$ ); however, it was a significant predictor of hospitalization secondary to cardiac decompensation (OR: 6.78, 95\% Cl: 2.28-20.13, $p=0.001)$.

Conclusions Minimal CAD was observed in $38 \%$ of DCMP patients. The risk factor profile predicting CAD in DCMP patients was the same as that of the general population. The presence of minimal CAD in DCMP patients was not associated with mortality. However, it was associated with hospitalization secondary to cardiac decompensation in the form of heart failure.
\end{abstract}

published online January 19, 2022
DOI https://doi.org/ $10.1055 / \mathrm{s}-0041-1739127$. ISSN 2455-7854.
(C) 2022. Women in Cardiology and Related Sciences. All rights reserved.

This is an open access article published by Thieme under the terms of the Creative Commons Attribution-NonDerivative-NonCommercial-License, permitting copying and reproduction so long as the original work is given appropriate credit. Contents may not be used for commercial purposes, or adapted, remixed, transformed or built upon. (https://creativecommons.org/ licenses/by-nc-nd/4.0/)

Thieme Medical and Scientific Publishers Pvt. Ltd., A-12, 2nd Floor, Sector 2, Noida-201301 UP, India 


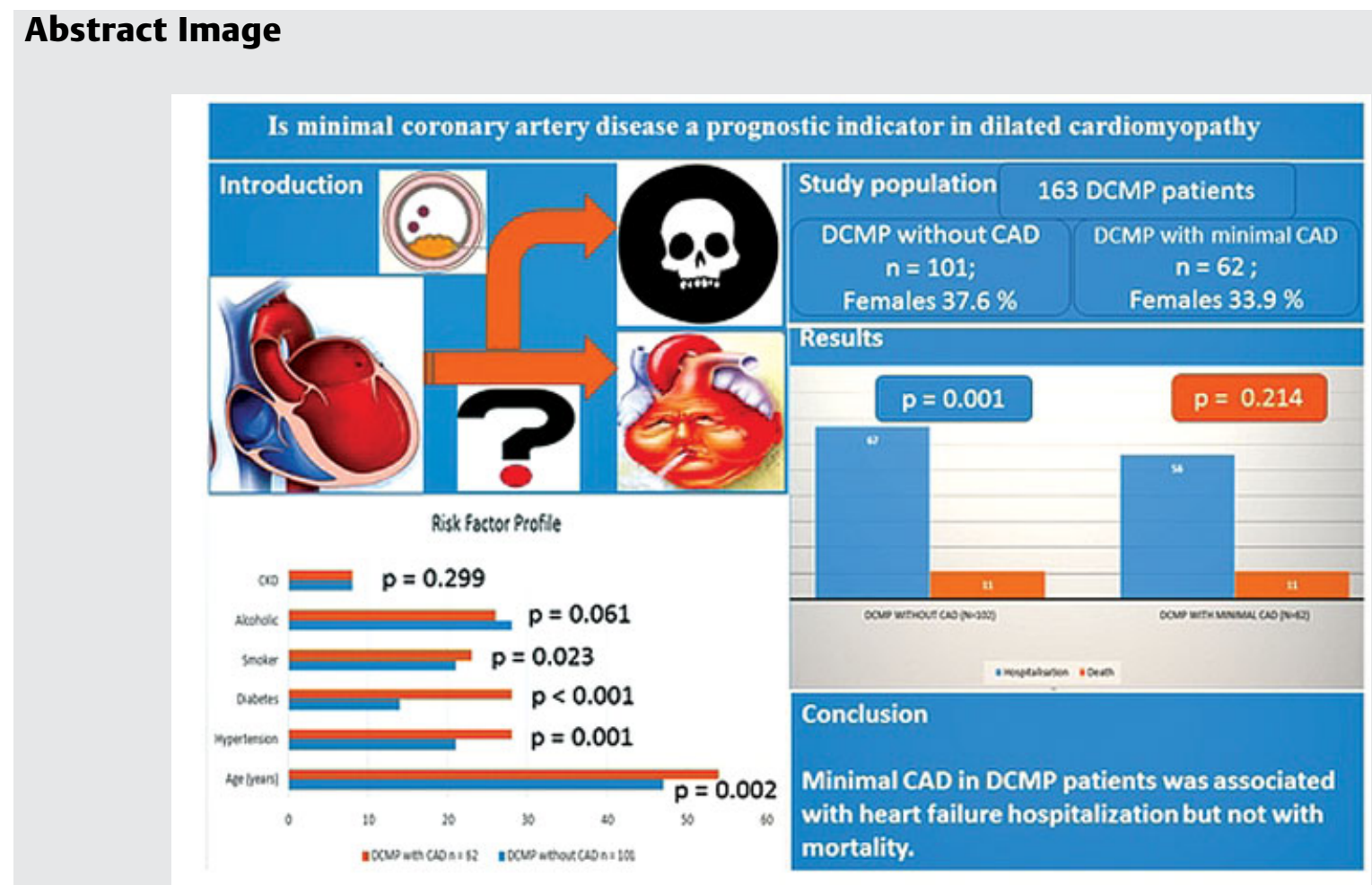

\section{Introduction}

Dilated cardiomyopathy (DCMP), as per the European Society of Cardiology 2008, is described as the dilatation and systolic dysfunction of the left ventricle, excluding conditions such as hypertension and valvular heart diseases that cause abnormal loading or coronary artery disease (CAD) sufficient to cause systolic dysfunction. ${ }^{1}$ It is almost similar to the American Heart Association definition. ${ }^{2}$ DCMP patients may have an associated CAD. ${ }^{3}$ The clinical profile of these patients is largely unknown. DCMP patients with associated CAD have been described on explanted hearts, that too, in a smaller group of studies. ${ }^{4-7}$ Presently, magnetic resonance imaging has evolved as a substitute for the coronary angiogram (CAG) for ruling out CAD. ${ }^{8}$ The amount of data about this issue other than these pathoanatomic studies has been of few case reports. ${ }^{9,10}$ The future risk and prognosis of an associated minimal CAD (stenosis $<50 \%$ ) in patients with DCMP are not clear. Some studies have shown a difference in outcome between patients with ischemic and nonischemic cardiomyopathy. ${ }^{11,12}$ In these studies, there appears some possibility of prognostic significance for associated minimal CAD (stenosis $<50 \%$ ) in DCMP patients. In our study, we tried to establish the risk factor profile and prognostic significance in terms of hospitalizations secondary to heart failure and mortality of DCMP patients with associated minimal CAD vis-à-vis normal coronaries in our cardiology department at Nizam's Institute of Medical Sciences (NIMS) hospital.

\section{Aims and Objectives}

The aim of this study was to study the effect of minimal CAD in DCMP patients on mortality and heart failure hospitalizations at follow-up of 30 months.

\section{Materials and Methods}

We enrolled a total of 163 patients with DCMP who had chronic systolic dysfunction in this study. Patients were admitted to the cardiology department of our institute for the evaluation of heart failure.

The study has local ethics committee approval.

\section{Inclusion Criteria}

1. DCMP patients with chronic systolic dysfunction.

2. Before undergoing CAG, patients were on required medical treatment for a minimum of 2 weeks.

3. CAG showed either normal coronaries or minimal CAD.

4. Minimal CAD was defined when angiographic luminal narrowing was $<50 \%$.

\section{Exclusion Criteria}

Following patients with a history of heart failure due to

A. Diseases of pulmonary parenchyma/vasculature.

B. Ischemic heart disease defined as having $>50 \%$ lesion in any coronary artery on CAG or history of myocardial infarction or history of coronary intervention or history of coronary artery bypass surgery. 


\section{Organic valvular heart disease. \\ D. Hypertrophic cardiomyopathy.}

\section{Determination of Cause of Heart Failure}

Heart failure was diagnosed as the presence of symptoms consistent with the diagnosis and supported by the functional abnormality ${ }^{13,14}$ on two-dimensional (2D) echocardiography. The ischemic cause of heart failure was ruled out on CAG, which revealed either normal coronaries or minimal CAD. ${ }^{1,2,15-17}$ After that patients with normal coronaries were grouped as DCMP without CAD (normal coronaries) and DCMP with minimal CAD. DCMP with minimal CAD group patients had insignificant coronary artery stenosis $(<50 \%$ luminal stenosis) in which the depressed left ventricular function could not be explained by the magnitude of stenosis. ${ }^{9}$

\section{Patient Profile}

History and physical examination of patients were done, and diagnostic testing, including detailed 2D echocardiography, was done in all patients during the initial workup. CAG was not done in the first admission for heart failure, as there was no evidence of ischemic heart disease. It was performed subsequently after a delay of 2 weeks of initial stabilization of heart failure. Comorbidities of the patient were noted.

\section{Follow-Up and Outcome}

The patients were followed up by scheduled visits to outpatient departments or by telephonic conversations to determine the survival status, as mortality was the primary endpoint of the study and cardiac decompensation in the form of heart failure requiring hospitalization was the secondary endpoint. All survivors of the cohort study were followed up for at least 30 months duration. None of the patients underwent cardiac transplantation or any other cardiac augmentation surgery during the follow-up period.

\section{Statistical Analysis}

A chi-squared analysis was performed to compare the frequencies between the two groups. Two-sample Wilcoxon's test and Student's $t$-test were used to test significant differences between means. Univariable and multivariable logistic regression was performed using the status of the coronary artery as independent variable, and death and hospitalization secondary to cardiac decompensation in the form of heart failure as a dependent variable and the results in the form of the unadjusted odds ratio (OR). Subsequently, the OR was adjusted for age and sex and then adjusted for age, sex, hypertension, diabetes, and smoking. Finally, the $p$-value was determined. Cox regression analysis was done for both the endpoints. All tests used for the statistical analysis of the study were two-tailed, and a $p$ value $<0.05 \%$ was considered significant. The demographic data were described as mean \pm standard deviation wherever it was deemed feasible.

\section{Results of the Study}

The final study population included were 163 patients out of which 101 had normal coronaries, classified as "DCMP without CAD group (normal coronaries)", and 62 patients with insignificant CAD as "DCMP with minimal CAD group."

There was no difference in sex distribution, alcohol consumption, and history of chronic kidney disease (CKD) between both groups. Patients with DCMP with minimal CAD differed from patients with DCMP without CAD (normal coronaries) in the risk factor profile prototypical for CAD such as age, hypertension, diabetes, and smoking (-Table 1).

Investigation parameters such as hemoglobin, creatinine, sodium, potassium, and mean ejection fraction between the two groups were compared as enumerated in -Table 2. However, the difference was found to be insignificant.

The total study population was followed up for 30 months, and it was found that $11(10.9 \%)$ patients expired in the DCMP without CAD (normal coronaries) group and 11 (17.7\%) patients in the DCMP with minimal CAD group. The results of the study revealed that 67 patients (66.3\%) in the DCMP without CAD (normal coronaries) group and 56 patients (90.3\%) in the DCMP with minimal CAD group

Table 1 Comparisons of demographic features in both groups

\begin{tabular}{|l|l|l|l|l|l|}
\hline & \multicolumn{2}{|l|}{$\begin{array}{l}\text { Without CAD }(\boldsymbol{n}=\mathbf{1 0 1}) \\
\boldsymbol{n} \%\end{array}$} & \multicolumn{2}{l|}{$\begin{array}{l}\text { With CAD }(\boldsymbol{n}=\mathbf{6 2}) \\
\boldsymbol{n} \%\end{array}$} & -Value $^{\mathbf{a}}$ \\
\hline Age (mean, SD) & $47.1,14.13$ & $54.0,12.02$ & $0.002+$ \\
\hline Male sex & 63 & 62.4 & 41 & 66.1 & 0.628 \\
\hline Hypertension & 21 & 20.8 & 28 & 45.2 & 0.001 \\
\hline DM & 14 & 13.9 & 28 & 45.2 & $<0.001$ \\
\hline Smoker & 21 & 20.8 & 23 & 37.1 & 0.023 \\
\hline Alcoholic & 28 & 27.7 & 26 & 41.9 & 0.061 \\
\hline CKD & 8 & 7.9 & 8 & 12.9 & 0.299 \\
\hline
\end{tabular}

Abbreviations: CAD, coronary artery disease; CKD, chronic kidney disease; DM, diabetes mellitus; SD, standard deviation.

${ }^{a}$ Chi-squared test unless specified; + unpaired $t$-test. 
224 Is Minimal CAD a Prognostic Indicator in DCMP? Kakroo, Kishore

Table 2 Two-sample $t$-test comparing the various investigative parameters between the two groups denoted by mean values \pm standard deviation. The $p$-value was calculated to observe for statistical significance

\begin{tabular}{|l|l|l|l|}
\hline Investigation parameters (mean values) & DCMP without CAD & DCMP with minimal CAD & $p$-Value \\
\hline Hemoglobin & $13.4 \pm 3.2$ & $12.8 \pm 2.8$ & 0.211 \\
\hline Creatinine & $1 \pm 0.2$ & $0.98 \pm 0.3$ & 0.643 \\
\hline Sodium & $135 \pm 10$ & $136 \pm 11$ & 0.561 \\
\hline Potassium & $3.8 \pm 0.6$ & $3.6 \pm 0.7$ & 0.064 \\
\hline Mean ejection fraction (\%) & $30 \pm 8$ & $29 \pm 8$ & 0.44 \\
\hline
\end{tabular}

Abbreviations: CAD, coronary artery disease; DCMP, dilated cardiomyopathy.

Table 3 Comparison of hospitalization and death rate between the two groups

\begin{tabular}{|l|l|l|l|}
\hline Parameters & $\begin{array}{l}\text { DCMP without } \\
\text { CAD }(\boldsymbol{n}=\mathbf{1 0 2})\end{array}$ & $\begin{array}{l}\text { DCMP with } \\
\text { minimal } \\
\text { CAD }(\boldsymbol{n}=\mathbf{6 2})\end{array}$ & $p$-Value \\
\hline Hospitalization & 67 & 56 & 0.001 \\
\hline Death & 11 & 11 & 0.214 \\
\hline
\end{tabular}

Abbreviations: CAD, coronary artery disease; DCMP, dilated cardiomyopathy.

developed acute decompensated heart failure requiring hospitalization during the follow-up period

(-Table 3; - Fig. 1).

\section{Prognostic Implications of Minimal CAD}

It was found that minimal CAD was not a significant predictor of mortality in univariable analysis. (OR: 1.76, 95\% confidence interval $[\mathrm{CI}]: 0.71-4.36, p=0.218)$. The result remained insignificant even after multivariable correction using logistic regression analysis with death (yes/no) as the dependent variable and CAD as the independent variable (OR: 1.69, 95\% CI: 0.62-4.62, $p=0.303$ ) (-Table 4).

However, minimal CAD was found to predict cardiac decompensation in the form of heart failure requiring hospitalization, and the result was statistically significant (OR: 4.74, 95\% CI: 1.85-12.70, $p=0.001)$. It remained significant even after multivariable correction (OR: 6.78, 95\% CI: $2.28-$ 20.13, $p=0.001$ ) (-Table 5).

In conclusion, the presence of minimal CAD in DCMP patients had more frequent hospitalization due to heart failure (90.3 vs. $66.3 \%$ ), which was statistically significant, but not the increase in mortality even though number-wise mortality was more (17.7 vs. $10.9 \%)$.

\section{Discussion}

In our study, the risk factor profile to predict CAD in DCMP patients was noted. The prognostic implications of associated minimal CAD in DCMP patients on mortality and

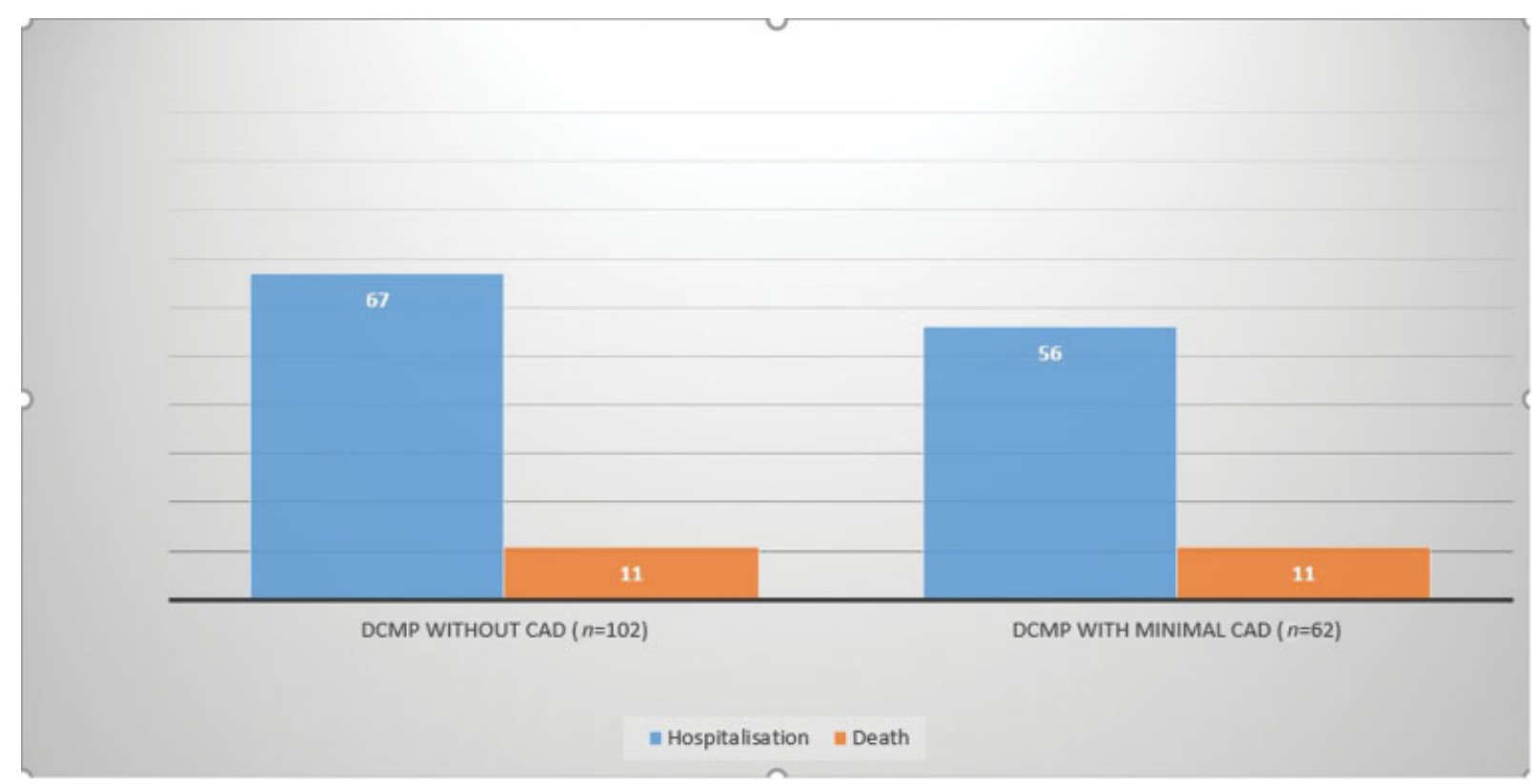

Fig. 1 Bar diagram comparing hospitalization and mortality between the two groups. CAD, coronary artery disease; DCMP, dilated cardiomyopathy. 
Table 4 Logistic regression analysis with death as the dependent variable and CAD as an independent variable

\begin{tabular}{|l|l|l|l|}
\hline & Unadjusted OR & OR adjusted for age and sex & $\begin{array}{l}\text { OR adjusted for age, sex, hypertension, } \\
\text { diabetes, and smoking }\end{array}$ \\
\hline OR & 1.76 & 1.56 & 1.69 \\
\hline $95 \% \mathrm{Cl}$ & $0.71-4.36$ & $0.61-3.96$ & $0.62-4.62$ \\
\hline$p$-Value & 0.218 & 0.351 & 0.303 \\
\hline
\end{tabular}

Abbreviation: $\mathrm{CAD}$, coronary artery disease; $\mathrm{Cl}$, confidence interval; OR, odds ratio.

Table 5 Logistic regression analysis with hospitalization secondary to cardiac decompensation as dependent variable and CAD as an independent variable

\begin{tabular}{|l|l|l|l|}
\hline & Unadjusted OR & OR adjusted for age and sex & $\begin{array}{l}\text { OR adjusted for age, sex, hypertension, } \\
\text { diabetes, and smoking }\end{array}$ \\
\hline OR & 4.74 & 4.86 & 6.78 \\
\hline $95 \% \mathrm{Cl}$ & $1.85-12.10$ & $1.86-12.70$ & $2.28-20.13$ \\
\hline$p$-Value & 0.001 & 0.001 & 0.001 \\
\hline
\end{tabular}

Abbreviations: $\mathrm{CAD}$, coronary artery disease; $\mathrm{Cl}$, confidence interval; $\mathrm{OR}$, odds ratio.

hospitalization secondary to cardiac decompensation in the form of heart failure were determined. However, in many studies, cardiomyopathy secondary to nonischemic cause and DCMP does not connote the same entity. Alternately, the degree of CAD might predict more regarding future events than the assigned cause. ${ }^{18-20}$ This would mean that the presence of an associated minimal CAD would not be of significant value in predicting future events in DCMP patients. However, some studies show worse outcomes for DCMP patients with associated CAD than those with normal coronaries in terms of heart failure hospitalization and death rates.

There has been only scarce data regarding DCMP with associated CAD. One of the recent studies ${ }^{21}$ concluded that concomitant CAD is frequent in DCMP patients. However, it does not predict mortality or hospitalization secondary to cardiac decompensation in these patients. ATLAS trial revealed that ischemia accounted for $9 \%$ of DCMP patients admitted in the hospital because of ischemia, and 19 patients died from myocardial infarction on follow-up out of a total of 1,129 patients. ${ }^{22}$ Similarly, in the SOLVD trial, $^{23} 164$ patients out of 586 patients with DCMP had ischemic events. Explanted hearts were studied to determine whether the initial cause leading to cardiomyopathy was correctly defined or not. ${ }^{4-7}$ The results obtained from this study showed a prevalence of significant CAD of around 23 to $27 \%$ in these specimens. Repetto et $\mathrm{al}^{6}{ }^{6}$ in his study, revealed that the prevalence of CAD in DCMP patients was around $65 \%$. However, our study revealed a prevalence of around $38 \%$. Repetto et $\mathrm{al}^{6}$ studied the presence and severity of CAD in his study population as predicted by the clinical factors ( - Table $\mathbf{6}$ ). In our study, we evaluated the effect of age, sex, hypertension, diabetes, smoking, alcohol, and CKD as a predictor of CAD in DCMP patients. The results were almost the same as those in the general population.

In one of the case reports, cardiac decompensation in longstanding DCMP patients was linked to CAD. ${ }^{10}$ It appears quite possible as chronic heart failure is atherogenic in itself. ${ }^{24}$

In our study, we found a significant association of CAD with cardiac decompensation in the form of heart failure requiring hospitalization. However, there was no association of associated insignificant CAD in DCMP patients related to mortality. Usually, the outcome of ischemic cardiomyopathy is worse than idiopathic

Table 6 Studies of concomitant CAD in DCMP patients

\begin{tabular}{|l|l|}
\hline Trials & Conclusion \\
\hline Frankenstein et $\mathrm{al}^{21}$ & $\begin{array}{l}\text { Concomitant CAD is common in DCMP patients. However, it is not a predictor of mortality } \\
\text { or heart failure }\end{array}$ \\
\hline Cleland et $\mathrm{al}^{22}$ & $9 \%$ of DCMP patients had ischemia, 19 out of 1,129 patients died from MI on follow-up \\
\hline Yusuf et $\mathrm{al}^{23}$ & 164 out of 586 DCMP patients had ischemic events \\
\hline Repetto et $\mathrm{al}^{6}$ & $65 \%$ prevalence of CAD in DCMP patients \\
\hline
\end{tabular}

Abbreviations: CAD, coronary artery disease; DCMP, dilated cardiomyopathy; MI, myocardial infarction. 
DCMP. $^{25,26}$ Moreover, both impairments in the coronary reserve $^{27}$ or positron emission tomography stress denoting perfusion-metabolism mismatch ${ }^{28}$ are related to a poor prognosis even in idiopathic DCMP patients. The result may be explained as the CAD in our study group was just a bystander (not the cause of cardiomyopathy) as opposed to ischemic heart disease in which it is the causal factor; thus, it does not bear the same prognostic significance. The second explanation for no significant difference in mortality may be strict follow-up and adherence to mortality benefit drugs, particularly beta-blockers.

The possible explanation for the association of minimal CAD in DCMP patients with an increase in hospitalization secondary to heart failure is that CAD in these patients may actively contribute to the diastolic abnormalities. The second explanation may be that the associated comorbidities such as hypertension, diabetes, older age, and smoking, which are higher in the DCMP with minimal CAD group, may impair diastolic function and thus increase in heart failure rates as compared with DCMP with normal coronaries group.

\section{Conclusion}

The risk factor profile predicting CAD in DCMP patients is the same as that in the general population. In our study, the presence of minimal CAD in DCMP patients was not associated with mortality. However, it is associated with hospitalization secondary to cardiac decompensation in the form of heart failure.

\section{Audio 1}

Audio file for this article is available at: https://doi.org/ 10.1055/s-0041-1739127.

\section{Conflict of Interest}

None.

\section{References}

1 Elliott P, Andersson B, Arbustini E, et al. Classification of the cardiomyopathies: a position statement from the European Society of Cardiology Working Group on Myocardial and Pericardial Diseases. Eur Heart J 2008;29(02):270-276

2 Maron BJ, Towbin JA, Thiene G, et al; American Heart Association Council on Clinical Cardiology, Heart Failure and Transplantation Committee Quality of Care and Outcomes Research and Functional Genomics and Translational Biology Interdisciplinary Working Groups Council on Epidemiology and Prevention. Contemporary definitions and classification of the cardiomyopathies: an American Heart Association Scientific Statement from the Council on Clinical Cardiology, Heart Failure and Transplantation Committee; Quality of Care and Outcomes Research and Functional Genomics and Translational Biology Interdisciplinary Working Groups; and Council on Epidemiology and Prevention. Circulation 2006;113(14):1807-1816

3 Esser S, Gelbrich G, Brockmeyer N, et al. Prevalence of cardiovascular diseases in HIV-infected outpatients: results from a prospective, multicenter cohort study. Clin Res Cardiol 2013;102 (03):203-213

4 Angelini A, Boffa GM, Livi U, Barchitta A, Casarotto D, Thiene G. Discordance between pre and post cardiac transplant diagnosis: implications for pre- and postoperative decision making. Cardiovasc Pathol 1999;8(01):17-23

5 Bortman G, Sellanes M, Odell DS, Ring WS, Olivari MT. Discrepancy between pre- and post-transplant diagnosis of end-stage dilated cardiomyopathy. Am J Cardiol 1994;74(09):921-924

6 Repetto A, Dal Bello B, Pasotti M, et al. Coronary atherosclerosis in end-stage idiopathic dilated cardiomyopathy: an innocent bystander? Eur Heart J 2005;26(15):1519-1527

7 Waller TA, Hiser WL, Capehart JE, Roberts WC. Comparison of clinical and morphologic cardiac findings in patients having cardiac transplantation for ischemic cardiomyopathy, idiopathic dilated cardiomyopathy, and dilated hypertrophic cardiomyopathy. Am J Cardiol 1998;81(07):884-894

8 McCrohon JA, Moon JC, Prasad SK, et al. Differentiation of heart failure related to dilated cardiomyopathy and coronary artery disease using gadolinium-enhanced cardiovascular magnetic resonance. Circulation 2003;108(01):54-59

9 Hedrich O, Jacob M, Hauptman PJ. Progression of coronary artery disease in non-ischemic dilated cardiomyopathy. Coron Artery Dis 2004;15(05):291-297

10 White BM, Mehta R, Binkley PF, Leier CV. Latent development of occlusive coronary atherosclerosis as a cause of decompensation of non-ischemic dilated cardiomyopathy. Cardiology 2009;112 (01):69-73

11 Adams KF Jr, Dunlap SH, Sueta CA, et al. Relation between gender, etiology and survival in patients with symptomatic heart failure. J Am Coll Cardiol 1996;28(07):1781-1788

12 Ghali JK, Krause-Steinrauf HJ, Adams KF, et al. Gender differences in advanced heart failure: insights from the BEST study. J Am Coll Cardiol 2003;42(12):2128-2134

13 Remme WJ, Swedberg KEuropean Society of Cardiology. Comprehensive guidelines for the diagnosis and treatment of chronic heart failure. Task force for the diagnosis and treatment of chronic heart failure of the European Society of Cardiology. Eur J Heart Fail 2002;4(01):11-22

14 McMurray JJ, Adamopoulos S, Anker SD, et al; Task Force for the Diagnosis and Treatment of Acute and Chronic Heart Failure 2012 of the European Society of Cardiology ESC Committee for Practice Guidelines. ESC guidelines for the diagnosis and treatment of acute and chronic heart failure 2012: the Task Force for the Diagnosis and Treatment of Acute and Chronic Heart Failure 2012 of the European Society of Cardiology. Developed in collaboration with the Heart Failure Association (HFA) of the ESC. Eur J Heart Fail 2012;14(08):803-869

15 Dickstein K, Cohen-Solal A, Filippatos G, et al; ESC Committee for Practice Guidelines (CPG) ESC Guidelines for the diagnosis and treatment of acute and chronic heart failure 2008: the Task Force for the Diagnosis and Treatment of Acute and Chronic Heart Failure 2008 of the European Society of Cardiology. Developed in collaboration with the Heart Failure Association of the ESC (HFA) and endorsed by the European Society of Intensive Care Medicine (ESICM). Eur Heart J 2008;29(19): 2388-2442

16 Hunt SA, Abraham WT, Chin MH, et al. 2009 focused update incorporated into the ACC/AHA 2005 Guidelines for the Diagnosis and Management of Heart Failure in Adults: a report of the American College of Cardiology Foundation/American Heart Association Task Force on Practice Guidelines: developed in collaboration with the International Society for Heart and Lung Transplantation. Circulation 2009;119(14):e391-e479

17 Wynne J, Braunwald $\mathrm{E}$. The cardiomyopathies and myocarditides. In: Braunwald E, Zipes DP, Libby P, eds. Heart Disease. Philadelphia: Saunders; 2001:1751-1806

18 Bart BA, Shaw LK, McCants CB Jr, et al. Clinical determinants of mortality in patients with angiographically diagnosed ischemic or nonischemic cardiomyopathy. J Am Coll Cardiol 1997;30(04): 1002-1008 
19 Felker GM, Shaw LK, O'Connor CM. A standardized definition of ischemic cardiomyopathy for use in clinical research. J Am Coll Cardiol 2002;39(02):210-218

20 Ndrepepa G, Tada T, Fusaro M, et al. Association of coronary atherosclerotic burden with clinical presentation and prognosis in patients with stable and unstable coronary artery disease. Clin Res Cardiol 2012;101(12):1003-1011

21 Frankenstein L, Hees H, Taeger T, et al. Clinical characteristics, morbidity, and prognostic value of concomitant coronary artery disease in idiopathic dilated cardiomyopathy. Clin Res Cardiol 2013;102(10):771-780

22 Cleland JG, Thygesen K, Uretsky BF, et al; ATLAS investigators. Cardiovascular critical event pathways for the progression of heart failure; a report from the ATLAS study. Eur Heart J 2001; 22(17):1601-1612

23 Yusuf S, Pepine CJ, Garces C, et al. Effect of enalapril on myocardial infarction and unstable angina in patients with low ejection fractions. Lancet 1992;340(8829):1173-1178
24 Cooke GE, Eaton GM, Whitby G, et al. Plasma atherogenic markers in congestive heart failure and posttransplant (heart) patients. J Am Coll Cardiol 2000;36(02):509-516

25 Franciosa JA, Wilen M, Ziesche S, Cohn JN. Survival in men with severe chronic left ventricular failure due to either coronary heart disease or idiopathic dilated cardiomyopathy. Am J Cardiol 1983; 51(05):831-836

26 Kelly TL, Cremo R, Nielsen C, Shabetai R. Prediction of outcome in late-stage cardiomyopathy. Am Heart J 1990;119(05):1111-1121

27 Pereira VF, de Carvalho Frimm C, Rodrigues AC, Cúri M. Coronary reserve impairment prevents the improvement of left ventricular dysfunction and adversely affects the long-term outcome of patients with hypertensive dilated cardiomyopathy. J Am Soc Hypertens 2010;4(01):14-21

28 de Jong RM, Tio RA, van der Harst P, et al. Ischemic patterns assessed by positron emission tomography predict adverse outcome in patients with idiopathic dilated cardiomyopathy. J Nucl Cardiol 2009;16(05):769-774 